This item was submitted to Loughborough's Research Repository by the author.

Items in Figshare are protected by copyright, with all rights reserved, unless otherwise indicated.

\title{
The effect of passive base ventilation on the aerodynamic drag of a generic SUV vehicle
}

PLEASE CITE THE PUBLISHED VERSION

http://dx.doi.org/10.4271/2017-01-1548

PUBLISHER

(C) SAE International

VERSION

VoR (Version of Record)

\section{PUBLISHER STATEMENT}

This work is made available according to the conditions of the Creative Commons Attribution-NonCommercialNoDerivatives 4.0 International (CC BY-NC-ND 4.0) licence. Full details of this licence are available at: https://creativecommons.org/licenses/by-nc-nd/4.0/

\section{LICENCE}

CC BY-NC-ND 4.0

\section{REPOSITORY RECORD}

Varney, Max, Martin Passmore, and Adrian P. Gaylard. 2017. "The Effect of Passive Base Ventilation on the Aerodynamic Drag of a Generic SUV Vehicle”. figshare. https://hdl.handle.net/2134/26321. 


\title{
The Effect of Passive Base Ventilation on the Aerodynamic Drag of a Generic SUV Vehicle
}

\author{
Max Varney and Martin Passmore \\ Loughborough University \\ Adrian Gaylard \\ Jaguar Land Rover
}

\begin{abstract}
Sports Utility Vehicles (SUVs) typically have a blunt rear end shape (for design and practicality), however this is not beneficial for aerodynamic drag. Drag can be reduced by a number of passive and active methods such as tapering and blowing into the base. In an effort to combine these effects and to reduce the drag of a visually square geometry slots have been introduced in the upper side and roof trailing edges of a squareback geometry, to take air from the freestream and passively injects it into the base of the vehicle to effectively create a tapered body.

This investigation has been conducted in the Loughborough University's Large Wind Tunnel with the $1 / 4$ scale generic SUV model. The basic aerodynamic effect of a range of body tapers and straight slots have been assessed for $0^{\circ}$ yaw. This includes force and pressure measurements for most configurations. The slots generate useful, but small, drag reductions with the best configurations giving reductions in drag coefficient $\left(\mathrm{C}_{\mathrm{d}}\right)$ of approximately 0.01 , whereas the best taper configurations reduce $\mathrm{C}_{\mathrm{d}}$ by close to 0.035 . The slots also have a tendency to modify the lift.
\end{abstract}

CITATION: Varney, M., Passmore, M., and Gaylard, A., "The Effect of Passive Base Ventilation on the Aerodynamic Drag of a Generic SUV Vehicle," SAE Int. J. Passeng. Cars - Mech. Syst. 10(1):2017, doi:10.4271/2017-01-1548.

\section{INTRODUCTION}

Aerodynamic drag is an increasing concern for vehicle manufacturers due to its impact on $\mathrm{CO}_{2}$ emissions and fuel economy. For instance, the European Union will phase in significant penalties for $\mathrm{CO}_{2}$ emissions above a mass-dependent limit curve from 2020 [1]. As Sport Utility Vehicles (SUVs) are the most popular body type [2] , the methods of reducing their drag come under closer scrutiny, specifically when the success of these vehicles owes much to elements of design and utility.

The blunt nature of SUV rear geometries arises from their historical use as working vehicles, with a need for maximal access to a large rear load space, whilst maintaining off-road capability. For squareback geometries, such as these, more than one-third of the aerodynamic drag is attributable to the rear surfaces [3] , resulting from separation at the trailing edges leading to low pressure on the base.
In order to combat the depressed static pressure on the base of vehicles a number of studies have been done to investigate base pressure recovery. Typical passive methods such as side tapering $[\underline{4}, \underline{5}]$, roof tapering $[\underline{4}, \underline{6}, \underline{7}, \underline{8}, \underline{9}]$, roughness strips $[\underline{10}]$ and underbody tapering $[11,12]$ have all been shown to result in base drag reductions. Active methods have also been tested with drag reductions being reported but little shown in terms of net energy reduction (as the systems require energy input); these include rolling trailing and leading edges [13], blowing [14] and thermal riblets [15].

Both passive and active methods alter the shear layers bounding the wake of the vehicle and, as a result change the base pressure and reduce drag. Typically the reduction in drag is shown to be due to the increase in base pressure $[\underline{4}, \underline{5}, \underline{7}, \underline{8}]$ but the resulting geometry changes also introduce other drag components (referred to by some as vortex drag [] $]$, slant pressure drag [ㅇ] or device drag [16]). Many of the geometries exhibit an optimum where the increase in the introduced drag contributions is minimal in comparison to the increase in base pressure. 
Varney et al / SAE Int. J. Passeng. Cars - Mech. Syst. / Volume 10, Issue 1 (April 2017)

Perry et al[4], Littlewood and Passmore [9] and Grandemange et al [7] have all investigated high aspect ratio (AR) roof tapers, (aspect ratio defined as taper span over taper length) and show that they produce drag reductions of the order of $1 \%$ on two different automotive bluff bodies. Grandemange et al shows this optimum to be at $6^{\circ}$ on low AR flaps that extend into the wake, due to the increasing base pressure on the upper half of the base (measured on the centerline) which corresponds to the shear layer being moved downwards; the upper shear layer interacts with the lower shear layer producing a slower recirculation on the lower base thus decreasing the pressure. Littlewood and Passmore shows an incremental base pressure increase across the entire base and Perry shows a high pressure region encroaching on the base from the sides of the model. Perry et al and Littlewood and Passmore also show that past the optimum (both showed this to be a $12^{\circ}$ taper) the increase in drag is a combination of the decreasing base pressure as well as the decreasing slant pressure.

Howell and Le Good [] ] shows that for a Windsor geometry the taper angle at which minimum drag occurs is dependent on the aspect ratio of the taper. For smaller aspect ratios the drag minimum is at a higher taper angle with a larger drag reduction $\left(\sim 5 \%\left[10^{\circ}\right]\right.$ at $\mathrm{AR}=2.25$ to $\sim 13 \%\left[15^{\circ}\right]$ at $\left.\mathrm{AR}=1.25\right)$ attributed to better pressure recovery over a much longer taper. To identify the origin of the reduction in drag the base, pressures are inferred from a vortex drag calculation based on the lift and drag. The increase in drag past the optimum is shown to be from the vortex drag component, or the slant pressure drag, whilst the base pressure drag continues to fall with the base area.

Perry et al [4] and Pavia et al [ [5] also consider tapering the sides of the model and both show that for high AR (8.66) tapers the optimum drag reductions are seen at $12^{\circ}$ for both the base pressure and the overall drag measurement. They conclude that the side tapers reduce the strength of the recirculating region and as such increase the base pressure. Past the optimum the lower recirculating region becomes much stronger and has a more significant effect on reducing the base pressure.

The advantages of rear end tapering are evident, but lead to a rear end shape that for SUV manufacturers may be unacceptable. Gaining the advantages in drag reduction from tapering, while preserving the external square shape, would allow for more design freedom. This might be achieved with active flow control methods, or passively by introducing ducting that feeds into the base area. This latter approach is sometimes referred to as base ventilation.

Suryanarayana [17] carried out passive ventilation on a sphere by ducting air from the front of the sphere to the base with a duct that was $15 \%$ of the diameter of the sphere, producing drag reductions of up to $60 \%$. The ventilation resulted in a ring shaped stagnation at the front of sphere and a toroidal recirculating region, due to an additional shear layer, at the base of the model. Suryanarayana [18] went on to show that by introducing the ventilation, and integrating the pressures over the sphere, that the pressure drag nearly becomes zero at supercritical Reynolds numbers.
In a similar method to Suryanarayana, Irving Brown et al. []ㅡ used a passive base bleed system to deliver flow from the front to the rear of a full scale SUV. This work used straight ducts and showed that depending on the location of the outlet of the ventilation in the wake the resulting difference in drag can be up to a $1 \%$ increase to nearly a $2 \%$ decrease. The best reduction in drag arose when the ventilation was introduced at the top and side edges, although it is not made clear where the flow is taken from in this instance.

Bartow and Hirst $[\underline{19}, \underline{20}]$ carried out similar work on wing mirror geometries. Bartow et al [20] used an automotive mirror with a bell shaped internal geometry to duct the flow to the base of the mirror, this flow was vented circumferentially. Whilst no experimental force measurements were presented for these geometries, particle image velocimetry (PIV) shows that increasing the intake area increases the mass flow rate and as a result reduces the size of the wake. Hirst et al [19] uses a truck type mirror with an intake placed on the outside of the geometry at the trailing edge, this ventilates the base circumferentially. When the ventilation is introduced the size of the wake decreases at both Reynolds numbers tested with the computational analysis showing a drag reduction of approximately $15 \%$.

The focus of the work reported in this paper is on the effect of ventilation introduced by floating trailing edges located over large side and rear upper body tapers. The general arrangement is illustrated in Figure 1. The paper considers the effectiveness of the tapers alone and then of using the external floating edge to form the duct. The influence of duct width is considered and the results of balance measurements and base pressure are presented.

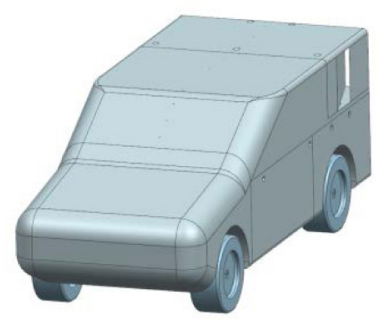

(a). Side Ventilation

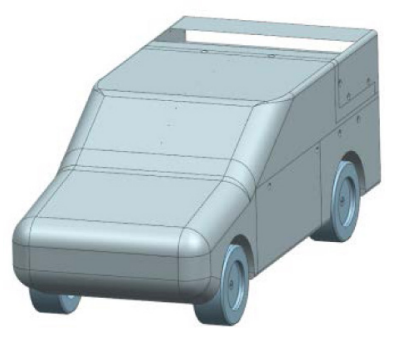

(b). Roof Ventilation

Figure 1. Slotted Geometries on the Generic SUV Geometry 
Varney et al / SAE Int. J. Passeng. Cars - Mech. Syst. / Volume 10, Issue 1 (April 2017)

\section{EXPERIMENTAL SET UP}

\section{The Facilities}

All testing was carried out in the Loughborough University Large Wind Tunnel (Figure 2). This tunnel is an open return, closed working section design capable of flow speeds up to $45 \mathrm{~m} / \mathrm{s}$ with a turbulence intensity of $0.2 \%$, a flow uniformity of $\pm 0.4 \%$ and a cross sectional area of $2.5 \mathrm{~m}^{2}[\underline{21}]$.



Figure 2. The Loughborough University Wind Tunnel [21]

\section{The Model}

The model used here is the $1 / 4$ scale Generic SUV model, seen in Figure 3 and first presented by Wood et al [22]. This model results in a blockage of $5.6 \%$ and is tested at a non-dimensional ride height $\left(h^{*}\right.$ $=h / H$ ) of 0.21 (where $h$ is the ride height and $H$ is the height of the model base). All the rear edges of the model are sharp and all longitudinal edges have a $10 \mathrm{~mm}$ radius. It has been designed in a modular way so that the upper $40 \%$ of the base can be fitted with a taper. All geometries tested are made of either dimensionally stable model board (of varying densities, manufactured on a 3-axis mill) or $3 \mathrm{D}$ printed from a rigid opaque material.

The principal dimensions of the generic SUV are an overall length of $1040 \mathrm{~mm}, 315 \mathrm{~mm}$ base height, $410 \mathrm{~mm}$ base width, $340 \mathrm{~mm}$ track and a $650 \mathrm{~mm}$ wheel base.

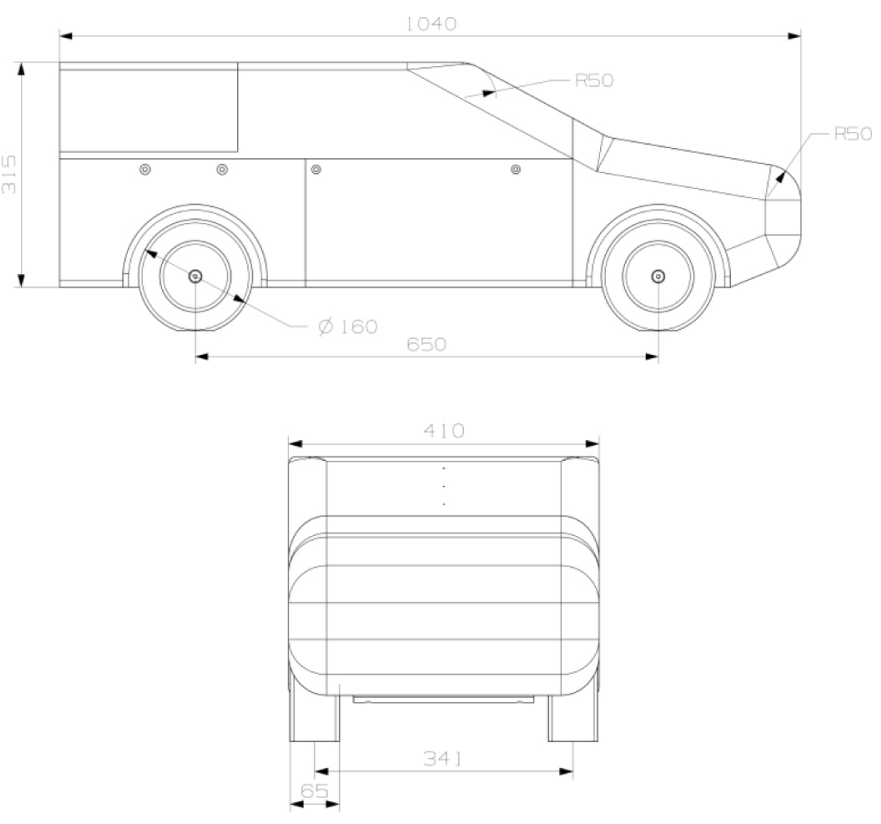

The coordinate system set out in SAE J1594 [23] is used throughout this paper with the origin located mid-wheelbase, mid-track and on the floor of the tunnel. The model is supported by four, $8 \mathrm{~mm}$ diameter pins protruding into the working section, on which the model wheels sit. The wheels are set to have $4 \mathrm{~mm}$ clearance from the tunnel floor when the tunnel is off. No correction has been made for the pins. The length based Reynolds number used throughout is $2.7 \times 10^{6}$.

A range of roof and side tapers were tested prior to the passive base ventilation (Figure 4(a) and Figure 4(b)) . All the tapers had a length (along the $\mathrm{x}$-axis) of $190 \mathrm{~mm}(60 \%$ model height, resulting in a range of aspect ratios of 2.03 to 2.16 ) tested at $5^{\circ}, 10^{\circ}, 15^{\circ}$ and $20^{\circ}$ with the side tapers only being implemented on the upper $40 \%$ of the model.

For the passive ventilation only straight ducts (Inlet and Outlet are identical) have been tested, with perpendicular distances from the tapered surface to the inner duct being between $5 \mathrm{~mm}$ and $25 \mathrm{~mm}$ (in steps of $5 \mathrm{~mm}$ ), as seen in Figure 4(c). The passive ventilation has been tested in combination with $10^{\circ}$ and $15^{\circ}$ side tapers and a $15^{\circ}$ roof taper.

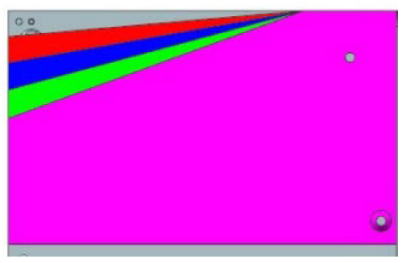

(a). $5^{\circ}$ to $20^{\circ}$ Side Tapering

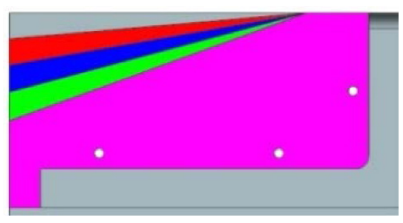

(b). $5^{\circ}$ to $20^{\circ}$ Roof Tapering

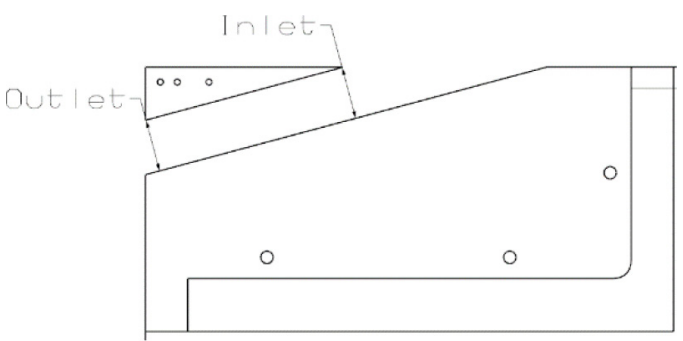

(c). Vane Ventilation Geometry Definition on the $15^{\circ}$ Roof Taper

Figure 4. (a) Side Tapering, (b) Roof Tapering and Diffuser Geometry, (c) $15^{\circ}$ Roof Taper Vane Description. 


\section{Balance Measurements}

All data was taken at $300 \mathrm{~Hz}$ for 300 seconds and averaged during post processing with typical confidence bounds being \pm 0.001 for $C_{d}$ and \pm 0.002 for $C_{l}$, calculated using Equation 1 .

$$
\bar{x} \pm z^{*} \frac{\sigma}{\sqrt{n}}
$$

\section{$\overline{\mathrm{X}}$ - Sample Mean}

z* - Upper Critical Value for the Standard Normal distribution

$\sigma-$ Standard Deviation

$\mathrm{n}$ - Sample Size

All coefficient calculations use a corrected value for the velocity estimated by using a continuity correction seen in Equation 2 [24].

$$
v_{\text {corrected }}=\frac{v \cdot A_{t}}{A_{t}-A_{m}}
$$

$\mathrm{A}_{\mathrm{t}}-$ Tunnel Area $\left(\mathrm{m}^{2}\right), \mathrm{A}_{\mathrm{m}}-$ Model Area $\left(\mathrm{m}^{2}\right), \mathrm{v}-\operatorname{Velocity}(\mathrm{m} / \mathrm{s})$

\section{Pressure Measurement}

The tapered surfaces and the base area of the model have been fully populated with a grid of pressure tappings (Figure 5). These tappings cover the entire model base to allow for any asymmetry to be characterized.

The pressure measurements were made with two 64 channel pressure scanners accurate to $\pm 0.15 \mathrm{~mm} \mathrm{H}_{2} \mathrm{O}$ with samples triggered at $260 \mathrm{~Hz}$. Data was taken for approximately 300 seconds.

All pressure results have been blockage corrected using a continuity based correction (Equation 3, [9]). The pressure coefficients on the model surface have been calculated using the freestream dynamic pressure that is measured far upstream of the model.

$$
C_{P-\text { corrected }}=\frac{C_{P}+2 \frac{A_{m}}{A_{t}}}{1+2 \frac{A_{m}}{A_{t}}}
$$

$C_{P}$ - Measured Surface Pressure Coefficient

The area weighted pressure coefficient presented in the results is calculated using Equation 4 [9] and shows a \pm 0.002 confidence value at a $99.9 \%$ confidence level for $\Delta \overline{C_{P}}$ (using Equation 1 ).

$$
\overline{C_{P}}=\frac{1}{A_{m}} \int_{A} C_{P} \cdot d A
$$

\section{$\overline{C_{P}}$ - Area Weighted Pressure Coefficient \\ dA - Area Over Which Each Measurement Location Acts}

Because all models show some small amount of asymmetry in both the yaw sweep and the base pressure distribution, an initial test to establish a common $0^{\circ}$ yaw position was performed. This used the $15^{\circ}$ roof taper configuration and working over a small range of yaw angles close to geometric zero the position that obtained the most symmetric base pressure distribution was determined and set as the $0^{\circ}$ yaw condition across all tests.

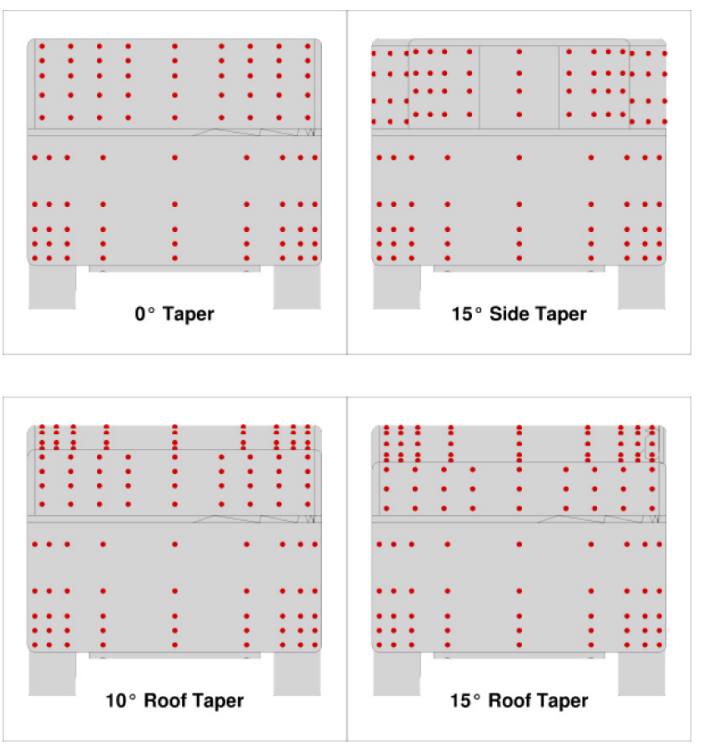

Figure 5. Pressure Tapping Locations Signified by Red Dots

\section{RESULTS AND DISCUSSION}

\section{Side Tapers}

The side tapering introduced here is on the upper $40 \%$ of the model only and has a length of $60 \%$ of the base height, the taper angles used are $5^{\circ}, 10^{\circ}, 15^{\circ}$ and $20^{\circ}$. Balance data was taken for all configurations but pressure data was only taken for the $0^{\circ}$ and the $15^{\circ}$ tapers.

At the common $0^{\circ}$ yaw the results show that the best drag reduction is the $15^{\circ}$ taper angle with a reduction of $\Delta C_{d}=-0.025$ relative to the un-tapered case (igure 6). The optimum determined here is at a somewhat higher angle than that obtained by Perry et al and Pavia et al $[\underline{4}, \underline{5}]$ of $12^{\circ}$; but it is a quite different model with significantly different slant aspect ratios. The reduction in drag is similar to that reported by Perry $\left(\Delta C_{d}=-0.02\right)$.

For the SUV model, the change in drag coefficient is due to a combination of the base and slant pressures with an increase in the area weighted base pressure of 0.042 , as calculated with Equation 4 , partially offset by a contribution from the slanted surfaces of 0.017 , also calculated with Equation 4, to give the overall reduction of 0.025 . The pressure distribution (Figure 7, the change in contour levels represents a change in $\mathrm{C}_{\mathrm{p}}$ of 0.01 , consistent throughout) indicates a significant change in the flow structure when the slant is 
introduced that is driven by the pressure recovery on the tapers. Without the tapers the wake is dominated by upwash and a U-shaped recirculation, but when a $15^{\circ}$ side taper is introduced this becomes a downwash dominated wake. Perry et al and Pavia et al [4,, 5$]$, when applying side tapers on the Windsor model, show that the increase in drag past the optimum is due to the increase in suction on the slant offsetting the increase in base pressure. So although pressure data is not available for all geometries tested here, the increase in drag from $15^{\circ}$ to $20^{\circ}$ seen for the SUV is also likely due to the suction on the leading edge of the slanted surface offsetting a further increase in base pressure.

Howell et al [25] showed, using the Windsor geometry but as here applying the tapering only to the upper half of the body, that the introduction of a shoulder into the geometry leads to the formation of a vortex which, in turn, generates downwash. This mechanism is likely to be present for the SUV with the streamwise vortices from the shoulder producing a downwash and an inwash resulting in a recirculation in the upper region of the base (low pressure and low fluctuations) and a downwash dominated wake.

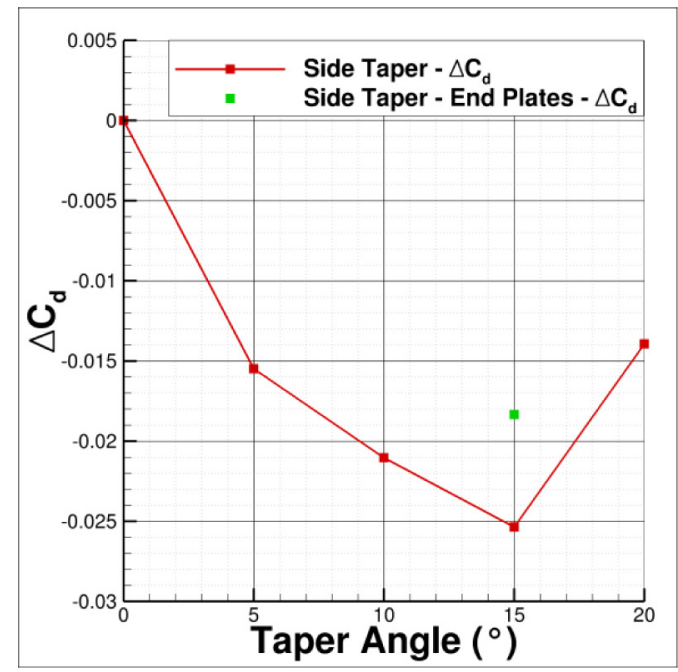

Figure 6. $\Delta C_{d}$ With Taper Angle for Side Tapering

In order to add the external parts necessary for the ventilated configuration a endplate is required on the upper part of the geometry (Figure $8 \mathrm{~b}$ ) and to complete the plain taper study the effect of this 'endplate' was explored on only the optimum configuration, as to not distract from the focus of this work. This is included on Figure 6 for the $15^{\circ}$ side taper and shows a smaller overall drag reduction of $\Delta C_{d}$ $=-0.018$ compared to without the endplate of -0.025 . The pressure distribution, Figure 7, shows that this is associated with lower pressure on the tapered surface when the endplate is installed. It is theorized that the lower pressure is caused by the weakening of the stream-wise vortices that are present in the no-endplate configurations and that aid pressure recovery along the side slant.



Figure 7. Pressure Distributions of End Plate Effects (Side Tapering)



(a). No Side Taper End Plate

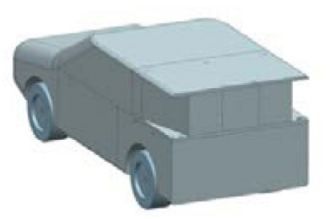

(b). Side Taper End Plate

Figure 8. Example of a Side Taper Endplate

The lift is also strongly affected by the side tapers (Figure 9), with an increase in lift coefficient of 0.08 for the optimum drag configuration compared to the square-back. The maximum $\Delta C_{L F}$ is $-0.009\left(10^{\circ} \mathrm{Side}\right.$ Taper), with other configurations showing smaller changes, as such the change in the lift coefficient is located at the rear axle. This increase likely arises from the progressive increase in lifting area on the shoulder between the taper and the body.

The effect on lift coefficient of the addition of the side taper end plate is also included on Figure 9. The suppression of the upper vortex structure leads to an expected reduction in lift. 


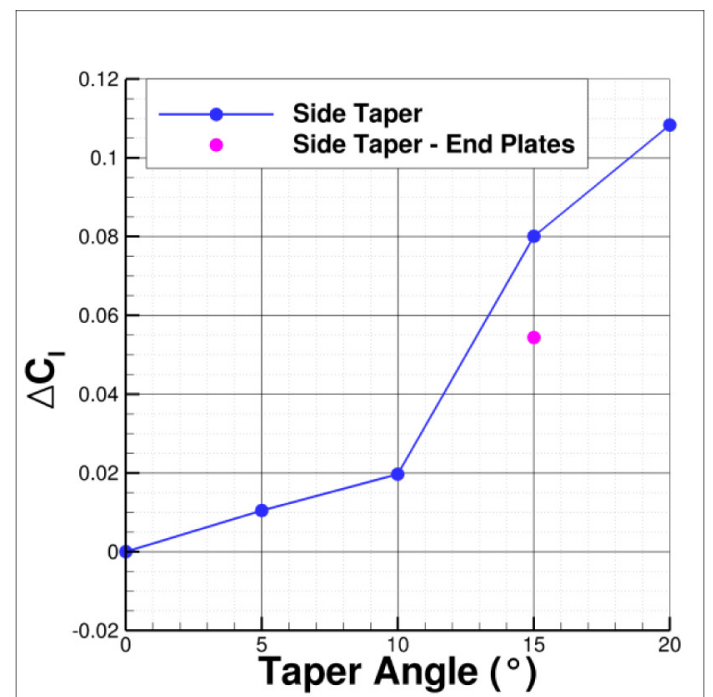

Figure 9. $\Delta C_{l}$ at $0^{\circ}$ Yaw with Taper Angle for Side Tapering

\section{Roof Tapers}

The roof tapers tested have length that is $60 \%$ of the base height. $0^{\circ}$, $5^{\circ}, 10^{\circ}, 15^{\circ}$ and $20^{\circ}$ taper angles have been tested.

The optimum drag reduction for the roof tapers is at $10^{\circ}$ with a drag reduction $\Delta C_{d}=-0.034$ (Figure 10). Calculating the area weighted contributions indicates a 0.051 increase in the base pressure offset by a reduction of 0.018 from the slant, both have been calculated using Equation 4. The contributions to the drag are summarized for all roof tapers in Figure 11. This shows increasing base pressure (reducing drag) up to the maximum angle tested, offset by large increases in the slant drag contribution.

The drag results are consistent with those shown by Howell and Le Good [] in magnitude with a similar optimum angle for a different model at a similar AR value. Howell went on to show that when increasing the AR of the taper, the angle at which the optimum drag reduction occurs decreases, this perhaps explains why the side tapers show a different optimum to Perry et al and Pavia et al [ㄴ,5].

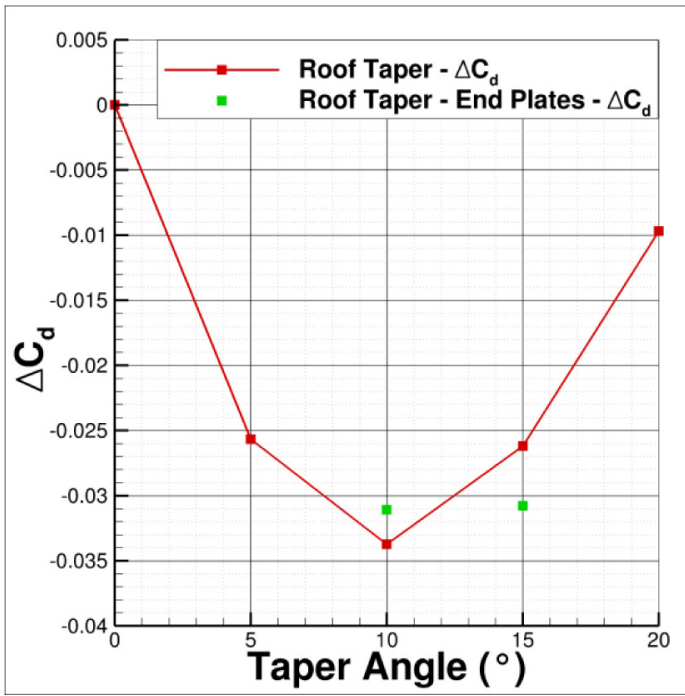

Figure 10. $\Delta C_{d}$ with Taper Angle for Roof Tapering



Figure 11. Drag Contributions with Roof Taper Angle

The pressure distributions illustrated in Figure 12 suggest a progressive change in the rear flow structure as more downwash is induced by the roof taper. The pressure fluctuations, presented in the form of contours of $C_{p}^{\prime} R M S$ (Figure 13, the change in contour level represents a change of $0.001 C_{p}^{\prime} R M S$, consistent throughout), reinforce this with most highly fluctuating region, indicative of the position of the rear impingement point, moving down into the lower central base.



Figure 12. Roof Tapering Pressure Distributions 
Varney et al / SAE Int. J. Passeng. Cars - Mech. Syst. / Volume 10, Issue 1 (April 2017)

The stream-wise vortices at the slant edges are clearly visible for taper angles above, $10^{\circ}$. These combined with the suction along the leading edge of the slant, are the dominant cause of the increasing measured drag for taper angles above $10^{\circ}$.

The lift coefficient (Figure 14) rises approximately linearly relative to the baseline case with an increase of 0.192 for the optimum drag configurations and 0.347 for the $20^{\circ}$ taper angle. The rise in lift coefficient can be attributed to the reduction in pressure on the tapered surface $\left(\Delta C_{L R}=0.316\right.$ for a $20^{\circ}$ roof taper), but also the pressure effects upstream of the taper $\left(\Delta C_{L F}=0.031\right.$ for the $20^{\circ}$ roof taper).



Figure 13. Roof Tapering Pressure Fluctuations

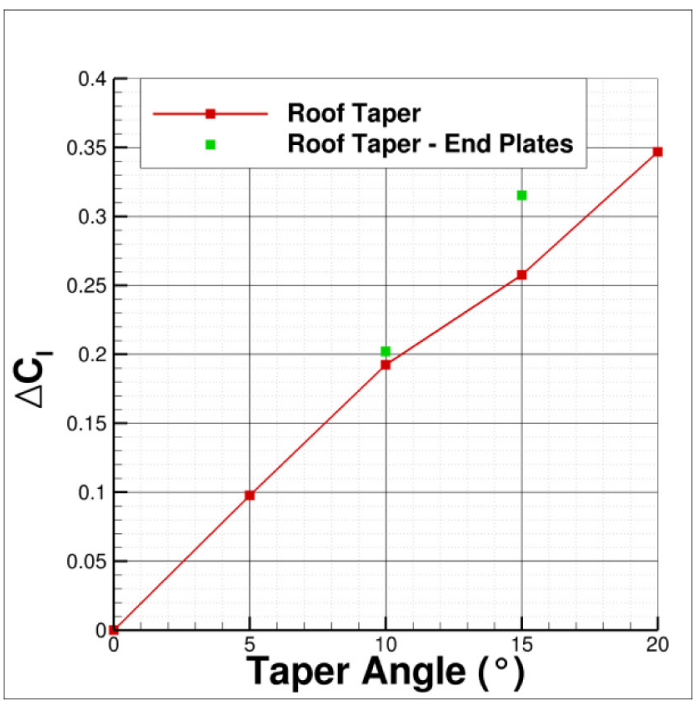

Figure 14. $\Delta C_{l}$ at $0^{\circ}$ Yaw with Taper Angle for Roof Tapering
When introducing end plates to the roof taper (Figure 15), again to facilitate the roof ventilation, the drag minimum shifts (at $0^{\circ}$ yaw) to between $10^{\circ}$ and $15^{\circ}$ with no distinct optimum. The reason for this is likely associated with the effect of the end plates on the strength of the stream-wise vortices formed at the edges of the tapers (see Figure $\underline{16}$ ), increasing the suction on the tapered surface with the resulting change in downwash altering the base pressure.



(a). No Roof Taper End Plates

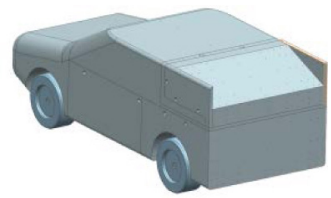

(b). Roof Taper Endplates

Figure 15. Example of an Roof Taper Endplates

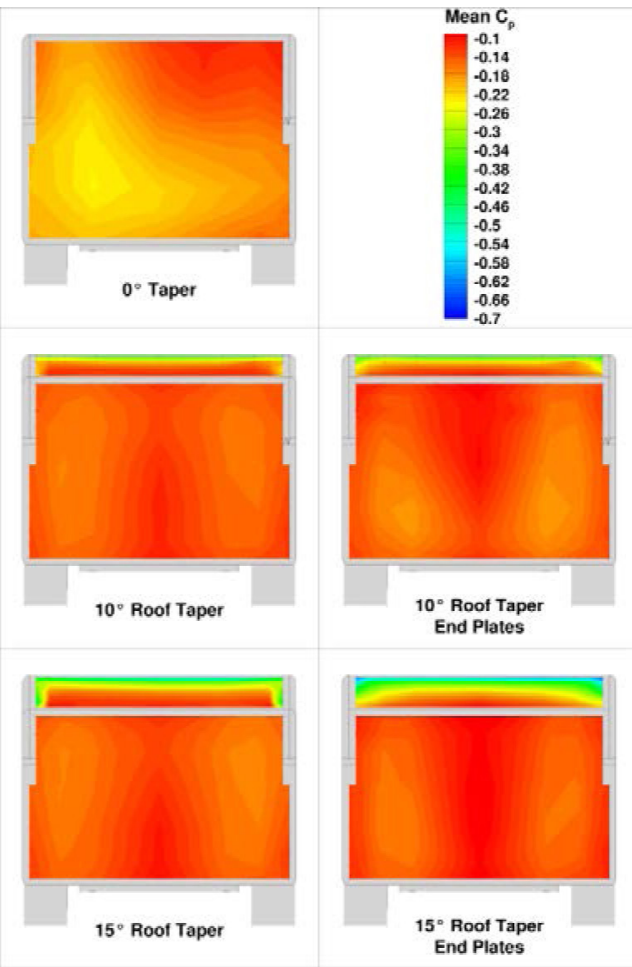

Figure 16. Pressure Distributions of End Plate Effects (Roof Tapering)

The increasing suction on the slanted surface from the introduction of the end plates can be seen both in the pressure contours (Figure 16) and the lift coefficient (Figure 14). The change in pressure on the slanted surface changes the drag contribution from the slant increasing this by 0.002 for the $10^{\circ}$ taper and by 0.007 for the $15^{\circ}$ taper. This is due to the reduced downwash onto the tapered surface which allows a greater suction. Both tapers increase the pressure on the base, with 0.002 and 0.013 for the $10^{\circ}$ and $15^{\circ}$ tapers relative to 
the no-endplate tapers. The discrepancy between the change in pressure drag and the change in measured drag is in part due to the introduced unmeasured base area on the end plates.

Maximizing rear load space is important for SUV's as they are utility vehicles. Figure 17 shows the drag reduction and entry area reduction with taper angle.

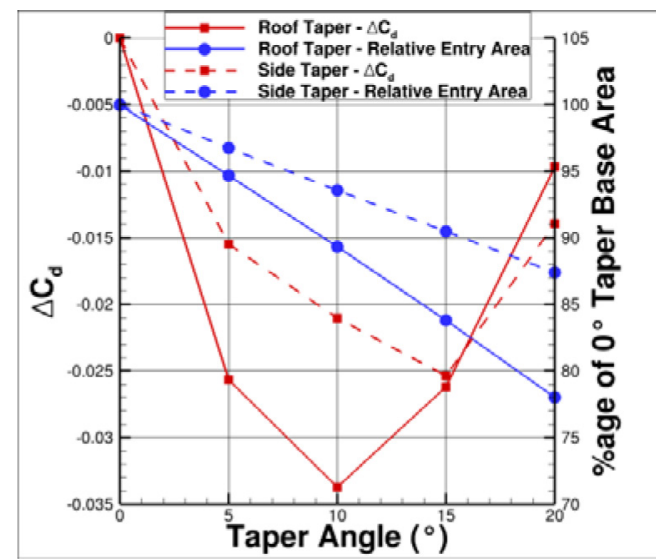

Figure 17. Drag Reduction $\left(0^{\circ}\right)$ and Base Area Reduction with Taper Angle

\section{Passive Base Ventilation}

The ventilation ducts have a straight profile with identical inlet and outlet dimensions (Figure 4c). The vane internal surface is parallel to the tapered surface throughout its length. The $10^{\circ}$ roof taper has a $5 \mathrm{~mm}, 10 \mathrm{~mm}$ and $15 \mathrm{~mm}$ width; these dimensions were limited by the geometry. Both the $15^{\circ}$ roof taper and the $15^{\circ}$ side taper use $5 \mathrm{~mm}$ to $25 \mathrm{~mm}$ widths (in steps of $5 \mathrm{~mm}$ ). The taper geometries were chosen as they are the lowest drag configurations for each taper type on this model, apart from the $15^{\circ}$ roof taper, which was chosen as it showed similar drag reductions in the endplate configuration to the $10^{\circ}$ roof taper. For all of these geometries, the base area of the introduced vane does not have any pressure measurement.

The $\Delta C_{d}$ values (at the common $0^{\circ}$ yaw) for each of the ventilated geometries (relative to an un-tapered baseline) can be seen in Figure $\underline{18}$, with an optimum for the $15^{\circ}$ tapers at $20 \mathrm{~mm}$ slot width. The $10^{\circ}$ roof taper achieved a drag optimum at $15 \mathrm{~mm}$ slot width, which provided both the lowest overall drag and largest ventilation effect; the latter giving a drag reduction of $\Delta C_{d}=-0.010$.

Both $15^{\circ}$ roof and side tapers show similar trends, with the optimum being a $20 \mathrm{~mm}$ slot width giving a $\Delta C_{d}$ of 0.008 . At lower slot widths there is some non-linearity in the trends, the side taper ventilation showing an initial drag increase. However, this variation is small falling within the $\pm 0.001 C_{d}$ balance measurement tolerance. A similar argument suggests that the $15^{\circ}$ roof taper ventilation has a broad optimum slot width range, extending from $10-20 \mathrm{~mm}$.

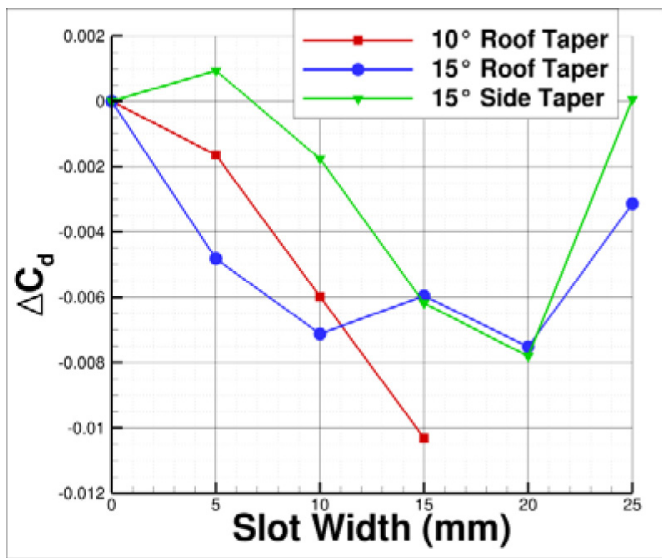

Figure 18. $\Delta C_{d}$ at $0^{\circ}$ Yaw with Slot Width



Figure 19. $\Delta C_{l}$ at $0^{\circ}$ Yaw with Slot Width

When introducing the vane geometry, the tapered lifting surface is now internal so no longer actively contributing to the pressure force, it is noted that there may be a pressure differential between the taper surface and the inner surface of the vane geometry which would contribute to the respective forces. However as the width of the slot increases, more of the tapered surface is exposed in the inlet region, simply as a result of the vane becoming smaller and therefore the lift increases. This can be seen in Figure 19 as a near linear trend in the lift with an increasing slot width for the roof ventilation.

Considering the skin friction drag, making the assumption that the wetted model area is directly proportional to the shear force and the assumption that the friction drag is $10 \%$ of the total drag, a change in the skin friction can be calculated. The maximum change in wetted area, from the baseline, is the $15^{\circ}$ roof taper with the $5 \mathrm{~mm}$ slot width at $7 \%$. When translating this to a change in $C_{d}$ it is $0.7 \%$, or $\sim 3$ counts.

As with the lift, the rearward facing component of the drag of the tapered surface can be calculated using Equation 4, interpolating between pressure tapping locations to find the $\mathrm{C}_{\mathrm{p}}$ value. The results of this calculation can be seen in Figure 21 with drag contributions of up to 0.021 . 
As the slot size increases, and the size of the vane decreases, the pressure in the slot reduces causing an increase in the slot drag contribution. This is due to the vane and endplates weakening the streamwise vortices that would otherwise increase the pressure on the tapered surface.

Due to the change in measured area, an initial rise can be seen in the area weighted base pressure (Figure 20), relative to the un-tapered baseline. Relative to the $5 \mathrm{~mm}$ slot width the trend is in agreement with that seen in Figure 18.

The increase in drag from the $20 \mathrm{~mm}$ to the $25 \mathrm{~mm}$ slots of 0.005 0.008 is the same order of magnitude as the change in contribution of the pressure drag. However, the pressure drag contribution of the vane geometry base is not considered.

When introducing a $5 \mathrm{~mm}$ slot, the base pressure distribution is similar to the un-tapered baseline due to the low speed flow injected by the ventilation into the wake. The low speed flow is evident due to the presence of a high pressure region on the slanted surface (Figure $\underline{22}$ and Figure 23). When the width of the slots is increased, the speed of the flow through the slot increases, as shown by a lower static pressure on the slant surfaces (Figure 22). This promotes the strengthening of the shear layers in the upper sides of the model, similar to that seen by Hirst and Bartow $[\underline{19}, \underline{20}]$.

For the $15^{\circ}$ roof taper ventilation (Figure 22), the base pressure distributions become incrementally more similar to the plain taper case as the slots become wider; it is believed that if the growth of the slot width is continued, it would eventually reach the 'endplate' taper base pressure distribution.

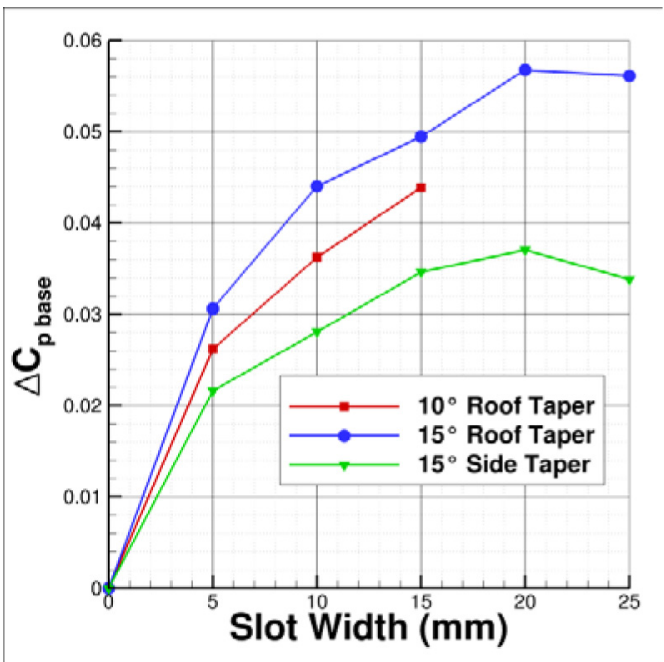

Figure 20. $\Delta \overline{C_{p \text { base }}}$ at $0^{\circ}$ Yaw with Slot Width

On the $15^{\circ}$ side taper ventilation, the shoulder vortices are unable to form due to the vane geometries. This causes a different trend (Figure $\underline{23}$ ) with the base pressure distribution changing incrementally to a more symmetrical, upwash dominated wake. By increasing the slot width further, providing the shoulder vortex is still suppressed, this trend is expected to continue.

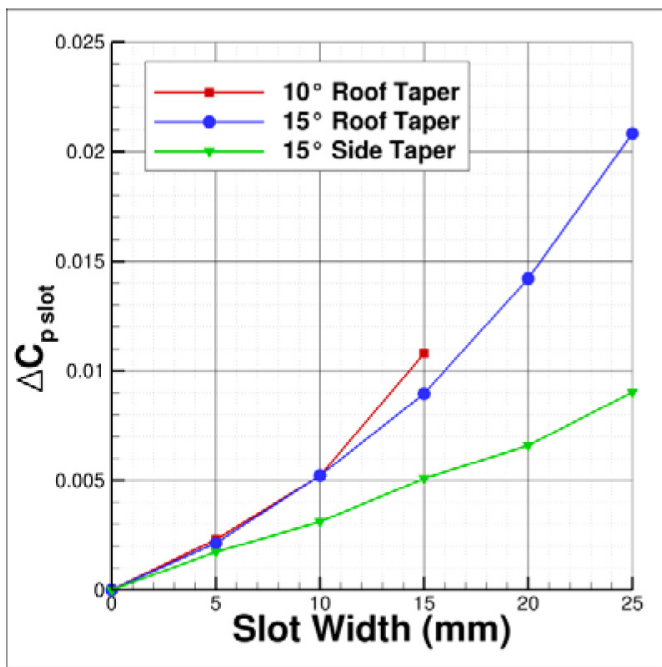

Figure 21. $\Delta \overline{C_{p \text { slot }}}$ at $0^{\circ}$ Yaw with Slot Width

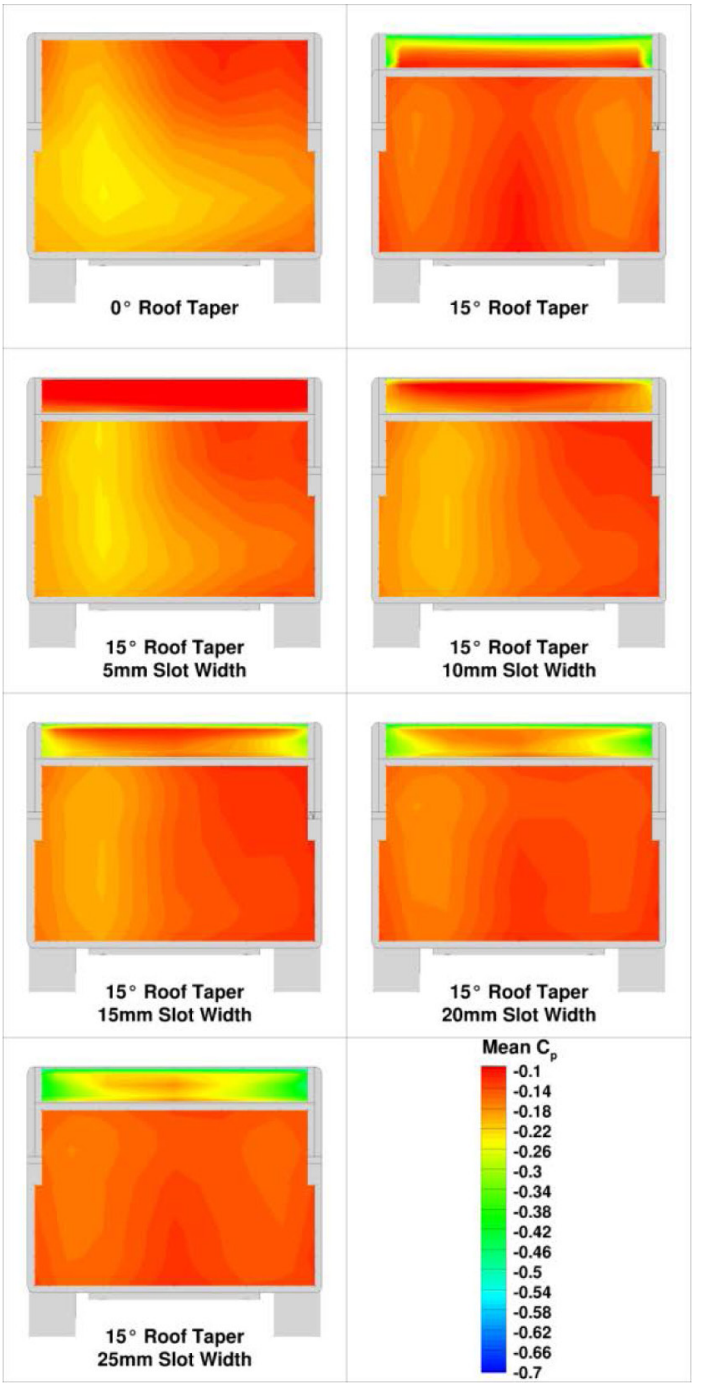

Figure 22. Pressure Distributions with Slot Width, $15^{\circ}$ Roof Taper 


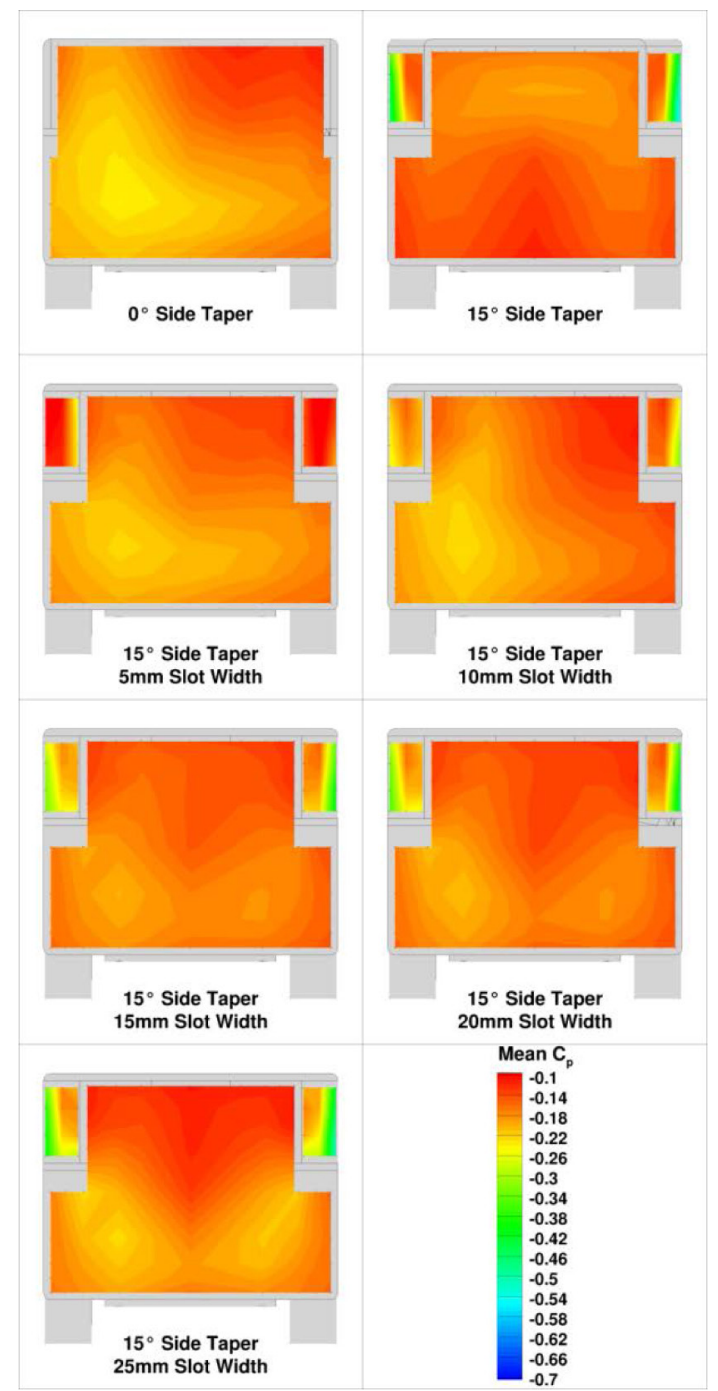

Figure 23. Pressure Distributions with Slot Width, $15^{\circ}$ Side Taper

\section{Bi-Stability}

Some of the geometries, considered in the present work show a phenomenon known as bi-stability (see Pavia et al [్], Grandemange [26]) in which the wake tends to randomly switch between two symmetry breaking states. When these states are averaged over a sufficiently long time period the result is an apparently symmetric flow field.

Only some of the configurations presented show this phenomenon, typically indicated by two distinct lobes of high Root Mean Square (RMS) values of the pressure fluctuations. The clearest cases are seen for $10^{\circ}$ roof taper and $15^{\circ}$ side taper ventilation geometries. For the $10^{\circ}$ roof taper (Figure 24 and Figure 25) the increasing downwash, due to increasing slot width, shows the two high RMS regions moving further down the base.

Figure 25 shows the time-history of $\mathrm{C}_{\mathrm{p}}$ at individual locations on the base of the model. Each time-history shows that there are two pressure states and switching between these states.
The $15^{\circ}$ side taper ventilation (Figure 25 and Figure 26) exhibits bi-stability, with the exception of the $10 \mathrm{~mm}$ slot case. This is believed to be due to the presence of an asymmetric base pressure distribution, which has been shown to have a significant impact on the bi-stability (Pavia et al []ㅡ). As the slot width is increased, the bi-stable region moves towards the center of the base, its location stabilizing for slot widths between $20 \mathrm{~mm}$ and $25 \mathrm{~mm}$.

The un-tapered baseline shows no signs of bi-stable behavior, believed to be due to the asymmetric pressure distribution. The $15^{\circ}$ roof taper ventilation geometries do not exhibit bi-stable behavior (Figure 27), perhaps due to the flow speeds being injected into the upper recirculation.

The endplates, used to hold the vane geometry, reduce the strength of the stream wise vortices; the presence of bi-stability for these configurations suggests that this phenomenon may be sensitive, not only to the level of downwash generated by the slanted surface (Pavia et al [27]), but also by the strength of these vortices.

Currently, the resulting shear layers from the slots for both the $10^{\circ}$ roof taper and the $15^{\circ}$ side tapers are not understood well enough to definitively say how the bi-stability is generated and should be the focus of further work.

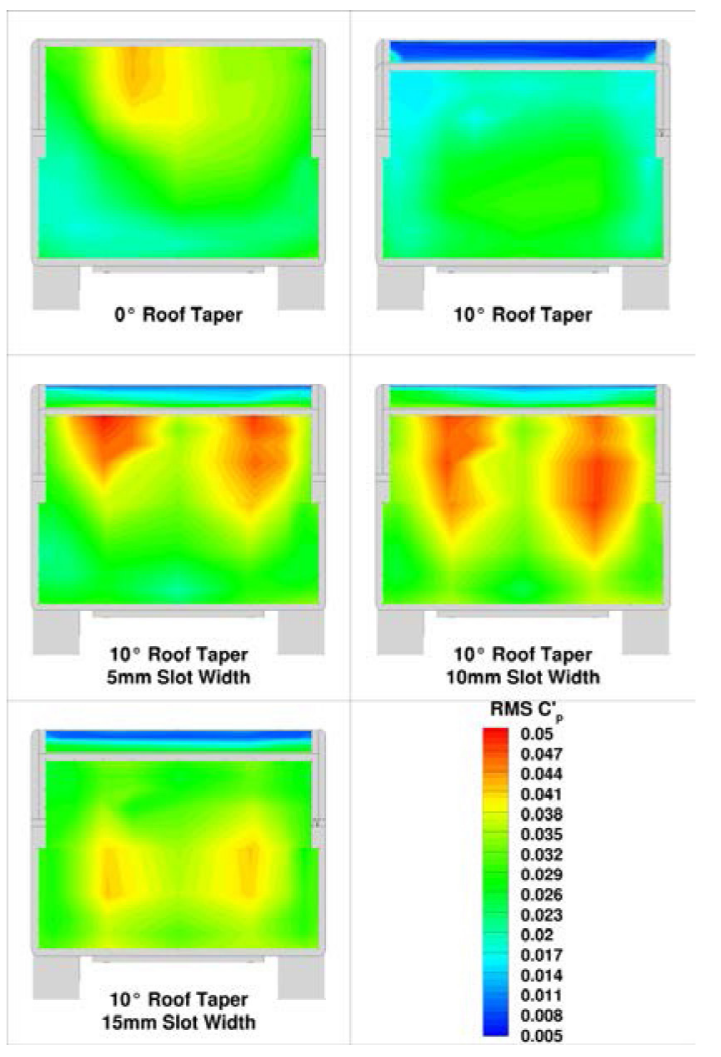

Figure 24. RMS of the Pressure Fluctuations for the $10^{\circ}$ Roof Taper Geometries 




$10^{\circ}$ Roof Taper - $5 \mathrm{~mm}$ Slot Width, Left Hand Side

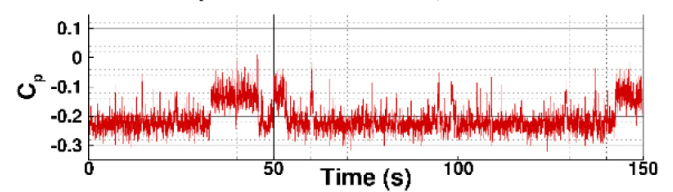

$15^{\circ}$ Side Taper - $5 \mathrm{~mm}$ Slot Width, Right Hand Side

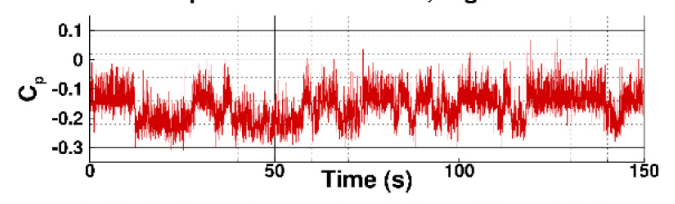

$15^{\circ}$ Side Taper $-5 \mathrm{~mm}$ Slot Width, Left Hand Side

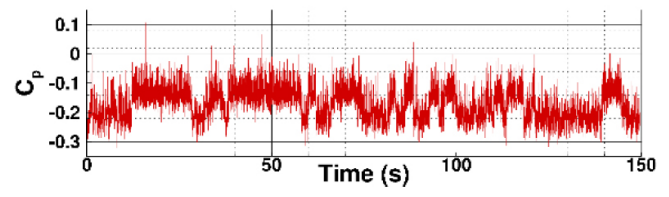

Figure 25. Pressure Traces Showing Bi-stable Behavior



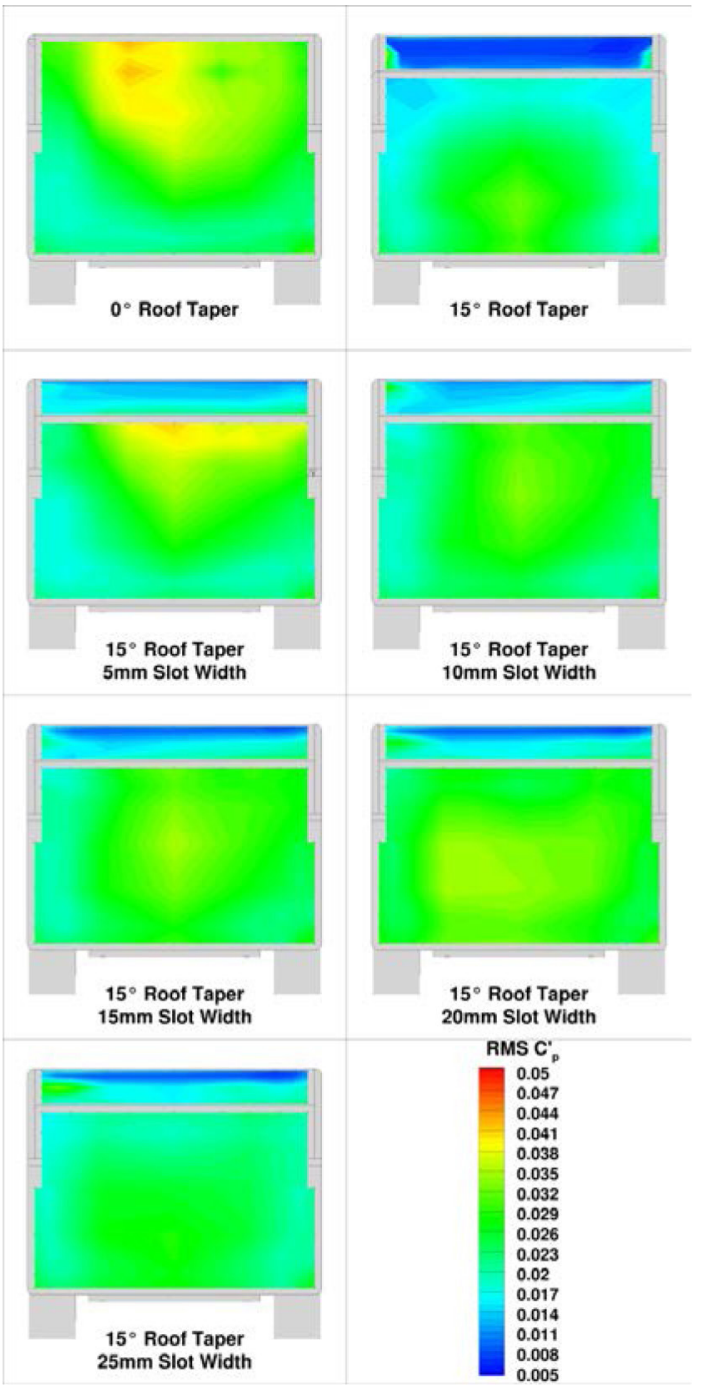

Figure 27. RMS of the Pressure Fluctuations for the $15^{\circ}$ Roof Taper Geometries

\section{SUMMARY/CONCLUSIONS}

The work presented here uses force and pressure measurements to investigate the usefulness of ventilated rear geometries on a $1 / 4$ scale automotive bluff body.

- For side tapers (on the upper $40 \%$ of the body) on the Generic SUV the optimum is $15^{\circ}$ producing a $\Delta C_{d}=-0.025$. This has been attributed to an increase in the base pressure.

- When considering roof tapers of the same length the optimum is $10^{\circ}$ with a $\Delta C_{d}=-0.034$. This is attributed to a rise in base pressure.

Figure 26. RMS of the Pressure Fluctuations for the $15^{\circ}$ Side Taper Geometries 
Varney et al / SAE Int. J. Passeng. Cars - Mech. Syst. / Volume 10, Issue 1 (April 2017)

Introducing ventilation into the base attempts to produce a

squareback shape with the benefits of a tapered surface.

- The best result was provided by a $10^{\circ}$ roof taper combined with a $15 \mathrm{~mm}$ wide slot, giving a drag reduction of $\Delta C_{d}=-0.010$.

- Using $15^{\circ}$ roof or side tapers with a $20 \mathrm{~mm}$ wide slot reduced drag by $\Delta C_{d}=-0.008$.

- In the case of the $15^{\circ}$ roof taper a slot width as low as $10 \mathrm{~mm}$ may actually have reached the optimum.

- Drag reductions from the ventilated geometries are not easily attributed to any one mechanism, but do show that there is an increase in base pressure when ventilation is introduced.

- The roof ventilation introduces increasing amounts of downwash, incrementally approaching that seen for an equivalent plain taper, this is not seen with side ventilation.

- Two of the ventilated configurations $\left(10^{\circ}\right.$ roof taper, $15^{\circ}$ side taper) show bi-stable behavior.

The introduction of the ventilation to the rear geometry shows a meaningful drag reduction against the baseline case, but this is not as large as those seen for the tapered surfaces alone.

The next stage of this work is to measure the pressure on the base area of the vane to develop insight into change on this surface. To fully characterize the drag reduction mechanisms associated with this type of ventilation it is appreciated that the shear layers need to be characterized. This will be undertaken using 2D planar particle image velocimetry supported by hotwire measurements.

\section{REFERENCES}

1. European Commission, "Reducing $\mathrm{CO} 2$ emissions from passenger cars," https://ec.europa.eu/clima/policies/transport/vehicles/cars/index_en.htm, accessed, Nov. 2016.

2. IHS Markit, "SUVs and Crossovers Overtake Sedans to Become Most Popular Vehicle Body Style in the U.S., IHS Automotive Finds," http:// news.ihsmarkit.com/press-release/automotive/suvs-and-crossoversovertake-sedans-become-most-popular-vehicle-body-style-, accessed, Nov. 2016.

3. Irving Brown, Y., Windsor, S., and Gaylard, A., "The Effect of Base Bleed and Rear Cavities on the Drag of an SUV," SAE Technical Paper 2010-01-0512, 2010, doi:10.4271/2010-01-0512.

4. Perry, A., Passmore, M., and Finney, A., "Influence of Short Rear End tapers on the Base Pressure of a Simplified Vehicle.," SAE Int. J. Passeng. Cars - Mech. Syst. 8(1):317-327, 2015, doi:10.4271/2015-01$\underline{1560}$.

5. Pavia, G., Passmore, M., and Gaylard, A., "Influence of Short Rear End Tapers on the Unsteady Base Pressure of a Simplified Ground Vehicle," SAE Technical Paper 2016-01-1590, 2016, doi:10.4271/2016-01-1590.

6. Howell, J. and Le Good, G., "The Effect of Backlight Aspect Ratio on Vortex and Base Drag for a Simple Car-Like Shape," SAE Technical Paper 2008-01-0737, 2008, doi:10.4271/2008-01-0737.
7. Grandemange, M., Mary, A., Gohlke, M., and Cadot, O., "Effect on Drag of the Flow Orientation at the Base Separation of a Simplified Blunt Road Vehicle," Experiments in Fluids 54(5), 2013, doi:10.1007/s00348013-1529-Z.

8. Ahmed, S., Ramm, G., and Faltin, G., "Some Salient Features Of The Time-Averaged Ground Vehicle Wake," SAE Technical Paper $\underline{840300}$, 1984, doi: $10.4271 / 840300$.

9. Littlewood, R. and Passmore, M., "The Optimization of Roof Trailing Edge Geometry of a Simple Square-Back.," SAE Technical Paper 201001-0510, 2010, doi:10.4271/2010-01-0510.

10. Perry, A. and Passmore, M., "The Impact of Underbody Roughness on Rear Wake Structure of a Squareback Vehicle," SAE Technical Paper 2013-01-0463, 2013, doi:10.4271/2013-01-0463.

11. Cooper, K., Bertenyi, T., Dutil, G., Syms, J. et al., "The Aerodynamic Performance of Automotive Underbody Diffusers," SAE Technical Paper 980030, 1998, doi:10.4271/980030.

12. Kowata, S., Ha, J., Yoshioka, S., Kato, T. et al., "Drag Force Reduction of a Bluff-Body with an Underbody Slant and Rear Flaps," SAE Int. J. Commer. Veh. 1(1):230-236, 2009, doi:10.4271/2008-01-2599.

13. Modi, V.J., Fernando, M., and Yokomizo, T., "Moving Surface Boundary-Layer Control as Applied to Two-Dimensional and ThreeDimensional Bluff Bodies," Journal of Wind Engineering and Industrial Aerodynamics 38(1):83-92, 1991, doi:10.1016/0167-6105(91)90029-V.

14. Littlewood, R.P. and Passmore, M.A., "Aerodynamic Drag Reduction of a Simplified Squareback Vehicle Using Steady Blowing," Experiments in Fluids 53(2):519-529, 2012, doi:10.1007/s00348-012-1306-4.

15. Yurchenko, N., "Thermal Riblets : Conceptual Approach to Flow Control," Proc. European Drag Reduction and Flow Control Meeting, 2015, Cambridge, UK, 35-37, 2015.

16. Howell, J., Sims-Williams, D., Sprot, A., Hamlin, F. et al., "Bluff Body Drag Reduction with Ventilated Base Cavities," SAE Int. J. Passeng. Cars - Mech. Syst. 5(1):152-160, 2012, doi:10.4271/2012-01-0171.

17. Suryanarayana, G.K., Pauer, H., and Meier, G.E.A., "Bluff-Body Drag Reduction by Passive Ventilation," Experiments in Fluids 16(2):73-81, 1993, doi:10.1007/BF00944909.

18. Suryanarayana, G.K. and Meier, G.E.A., "Effect of Ventilation on the Flowfield Around a Sphere," Experiments in Fluids 19(2):78-88, 1995, doi:10.1007/BF00193853.

19. Hirst, T., Li, C., Yang, Y., Brands, E. et al., "Bluff Body Drag Reduction Using Passive Flow Control of Jet Boat Tail," SAE Int. J. Commer. Veh. 8(2):713-721, 2015, doi:10.4271/2015-01-2891.

20. Bartow, W., Moreyra, A., Hirst, T., Woyczynski, G. et al., "Experimental Investigations of Vehicle Base Drag Reduction Using Passive Jet Boat-Tail Flow Control," SAE Technical Paper 2014-01-2448, 2014, doi: 10.4271/2014-01-2448.

21. Johl, G., "The Design and Performance of a 1.9mx1.3m Indraft Wind Tunnel," Ph.D. thesis, Aeronautical and Automotive Engineering, Loughborough University, 2010.

22. Wood, A., Passmore, M., Forbes, D., Wood, D. et al., "Base Pressure and Flow-Field Measurements on a Generic SUV Model," SAE Int. J. Passeng. Cars - Mech. Syst. 8(1):233-241, 2015, doi:10.4271/2015-01$\underline{1546}$.

23. SAE International Vehicle Aerodynamics Terminology, SAE Standard J1594, Rev Dec. 1994.

24. Cooper, K.R., "Closed-test-section Wind Tunnel Blockage Corrections for Road Vehicles. Special Publication SAE SP1176," Society of Automotive Engineers, SAE, 1996.

25. Howell, J., Passmore, M., and Tuplin, S., "Aerodynamic Drag Reduction on a Simple Car-Like Shape with Rear Upper Body Taper," SAE Int. J. Passeng. Cars - Mech. Syst. 6(1):52-60, 2013, doi:10.4271/2013-01$\underline{0462 .}$.

26. Grandemange, M., "Analysis and Control of Three-dimensional Turbulent Wakes: from Axisymmetric Bodies to Road Vehicles," Thesis, Ph.D. Thesis, ENSTA ParisTech, École Polytechnique, Paris, 2013.

27. Pavia, G., Perry, A.K., and Passmore, M., "Influence of Short Rear End Tapers on the Wake of a Simplified Square-Back Vehicle: Wake Topology and Rear Drag," Experiments in Fluids 57(11):169, 2016, doi:10.1007/s00348-016-2260-3. 
Varney et al / SAE Int. J. Passeng. Cars - Mech. Syst. / Volume 10, Issue 1 (April 2017)

\section{CONTACT INFORMATION}

Max Varney

Stewart Miller Building

Loughborough University

Loughborough, LE11 3TU, England

M.Varney@lboro.ac.uk

Martin Passmore

M.A.Passmore@,lboro.ac.uk
DEFINITIONS/ABBREVIATIONS

SUV - Sports Utility Vehicle

AR - Aspect Ratio

count -0.001 of a coefficient

RMS - Root Mean Square

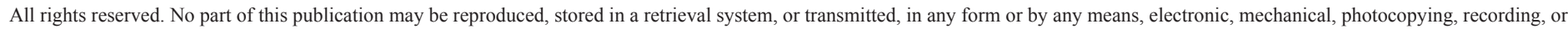
otherwise, without the prior written permission of SAE International

Positions and opinions advanced in this paper are those of the author(s) and not necessarily those of SAE International. The author is solely responsible for the content of the paper. 